\title{
Detection and Determination of Solute Carbon in Grain Interior to Correlate with the Overall Carbon Content and Grain Size in Ultra-Low-Carbon Steel
}

\author{
Jiling Dong, ${ }^{1,2}$ Yinsheng He, ${ }^{2}$ Chan-Gyu Lee, ${ }^{2}$ Byungho Lee, ${ }^{3}$ Jeongbong Yoon, ${ }^{3}$ \\ and Keesam Shin ${ }^{2, *}$ \\ ${ }^{1}$ School of Metallurgy and Materials Engineering, Chongqing University of Science and Technology, Chongqing 401-331, \\ China \\ ${ }^{2}$ School of Nano \& Advanced Materials Engineering, Changwon National University, Changwon 641-773, Korea \\ ${ }^{3}$ POSCO, Sheet Products \& Process Research Group, Technical Research Laboratories, Pohang 790-784, Korea
}

\begin{abstract}
In this study, every effort was exerted to determine and accumulate data to correlate microstructural and compositional elements in ultra-low-carbon (ULC) steels to variation of carbon content (12-44 ppm), manganese $(0.18-0.36 \%)$, and sulfur (0.0066-0.001\%). Quantitative analysis of the ULC steel using optical microscope, scanning electron microscope, transmission electron microscope, and three-dimensional atom probe revealed the decrease of grain size and dislocation density with the increase of carbon contents and/or increase of the final delivery temperature. For a given carbon content, the grain interior carbon concentration increases as the grain size increases.
\end{abstract}

Key words: ultra-low-carbon steel, solute carbon, atom by atom analysis, grain size, TEM, 3DAP

\section{INTRODUCTION}

Malleability is essential for forming, but higher strength is desired afterward for shaping parts such as automobile outer plates and steel cans. One way to achieve this is by taking advantage of Cottrell environment, in which solute atoms such as $\mathrm{C}$ and $\mathrm{N}$ migrate to dislocation during aging, and pin the dislocations resulting in the increased strength. By utilizing Cottrell effect, usage of expensive carbide formers such as $\mathrm{Nb}$ and $\mathrm{Ti}$ can be avoided, and increased bonding between the body and paint for longer life time and smoother surface to reduce the weight with improved safety, since most of the panels of the automobile bodies are desired to have higher strength coupled with better formability, which is why ULC steels are widely used for automobiles (Zhang et al., 2000; Berbenni et al., 2004; Cerezo \& Davin, 2007).

In this study, ULC steels of carbon content up to 100 appm were examined for the following: (1) the distribution of $\mathrm{C}, \mathrm{N}, \mathrm{S}$, and other minor additional elements in the grain interior, grain boundary, in dislocation, and in precipitates; (2) their evolution upon hot and cold rolling, skin pass, reflow, and aging; and (3) the mechanism involving Cottrell atmosphere formation.

\section{Experimental Procedure}

The ULC steel specimens were fabricated in POSCO via usual steps of the steel-making process. The sheets were reheated at $\sim 1,250^{\circ} \mathrm{C}$ and subsequently hot rolled to strips with the final delivery temperature (FDT) of $800^{\circ} \mathrm{C}$ (A specimens) and $900^{\circ} \mathrm{C}$ (G specimens), cold rolled, and then subjected to recrystallization annealing followed by skin-

() MICROSCOPY SOCIETY OF AMERICA 2013

${ }^{\star}$ Corresponding author. E-mail: keesam@changwon.ac.kr pass rolling (Ab specimens), reflow, and finally baking at $200^{\circ} \mathrm{C}$. The chemical compositions of the specimens are as follows: Mn, $<0.2 \mathrm{wt} \%$; P, $<50 \mathrm{ppm}$; S, $<100 \mathrm{ppm}$; Al, $<400 \mathrm{ppm}$; N, $<50 \mathrm{ppm}$; and with $10 \mathrm{ppm}$ (\#1 specimen) and $50 \mathrm{ppm}$ (\#4 specimen) carbon content. For \#28 specimen, the carbon content is similar to that of \#1 specimen, but the content of $\mathrm{Mn}$ is double, and S, P is half of \#1, in addition to $\sim 10 \mathrm{ppm} \mathrm{B}$.

All the specimens for optical microscope (OM) and scanning electron microscope (SEM) observation were prepared by metallographic polishing, followed by etching with $2 \%$ nital. The transmission electron microscopy (TEM) specimens were electropolished using 95\% acetic acid $+5 \%$ perchlolic acid solution at $15^{\circ} \mathrm{C}$. The specimens for the three-dimensional atom probe (3DAP) observation were electropolished using double-layer technique (Miller, 2000), followed by focused ion beam sharpening and final cleaning.

\section{Results AND Discussion}

\section{$\mathrm{OM}$ and TEM Analysis}

Figure 1a shows OM micrograph of the specimen with $10 \mathrm{ppm}$ of carbon content after skin-pass rolling (A1). A fine-grain structure of the specimen can be observed after skin-pass rolling. The average grain size (Table 1, left column) decreased with the increase of carbon content in all three groups of specimens, which is attributed to the fact that increase in carbon content decreases the $\gamma$ to $\alpha$ transformation temperature. In addition, it, in turn, reduces the completion temperature of $\gamma$ to $\alpha$, leaving less time for growth, which agrees well with the previous report (Lee et al., 2002). The grain sizes of $G$ specimens were smaller than those of A specimens, owing to the incompletion of $\gamma$ to $\alpha$ 


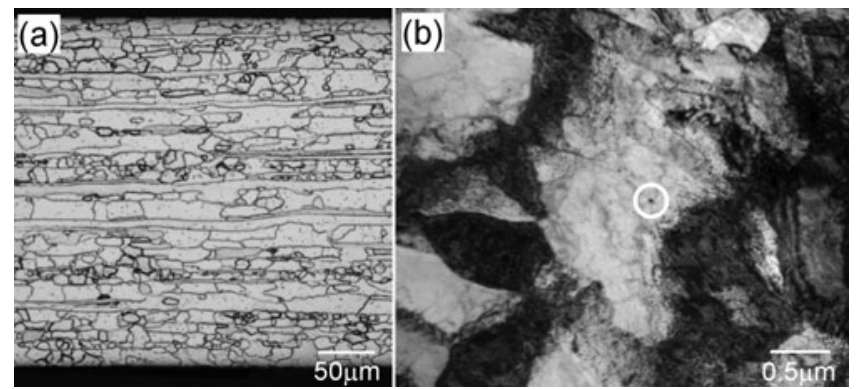

Figure 1. Typical optical microscope (a) and transmission electron microscope (b) micrographs of the Al specimen: (a) the grain morphology and size, and (b) the dislocation structure and the MnS precipitate (marked by circle).

transformation, leaving less time for growth. After baking, the average grain sizes of all the specimens increased, keeping the same trend among the specimen groups of $\mathrm{Ab}, \mathrm{A}$, and $\mathrm{G}$, which indicates that the refinement of grains can be obtained by increasing the FDT during hot rolling. Meanwhile, with the addition of $\mathrm{Mn}, \mathrm{B}$ and/or decrease of S, P, the grain sizes of the \#28 are larger than those of \#1.

The fact that the grain size of $\# 28$ specimens is larger than that of \#1 agrees well with the previous report, i.e., ferrite grains refine with reduction of $\mathrm{Mn}$ and/or addition of S (Takahashi, 1974), because the content of Mn is higher and $S$ is lower for \#28 than those in \#1. Also, the addition of $\mathrm{B}$ can obviously be another reason for the coarsening of ferrite grain. From OM and SEM analysis, no precipitates in any of the specimens were observed.

From TEM analysis of microstructural, compositional, and diffraction analyses, it was found that all of the precipitates in all the specimens were MnS (Fig. 1b), whose average size and area fraction reduced in accordance with the increase of carbon contents and decrease of S/Mn ratio. Higher number density of MnS was observed in \#1 than that in \#28, which is attributed to the lower $\mathrm{S}$ content in \#28. With higher carbon content, the dislocation density was observed to be lower.

\section{DAP Analysis}

Many researchers have used the maximum spacing $\left(d_{\max }\right)$ between solute atoms as a way of defining the atoms that belong to a single precipitate or cluster (Heinrich et al., 2003). To find the optimum parameter for carbon cluster analysis, the $d_{\max }$ is changed from 0.5 to $3 \mathrm{~nm}$, and the $N_{\min }$ (minimum number of solute ions in cluster to be considered a cluster) is changed from 3 to 7 ions. A smaller $d_{\max }$ will result in fewer false positives during the cluster search, whereas a larger $d_{\max }$ includes more clusters. In addition, an optimized cluster size limit for subsequent cluster detection can be at or above the maximum of the randomized distribution. The use of a minimum cluster size in ions, smaller than the random value ( $\sim 3$ in this sample), would result in more false-positive clusters detected. Thus, in this study, the optimum parameter for carbon cluster analysis is set to be $d_{\max }=2.5 \mathrm{~nm}$ and $N_{\min }=3$ ions.

3DAP analysis was performed under voltage pulse with a pulse fraction of $20 \%$ and a pulse rate of $200 \mathrm{kHz}$ at $40 \mathrm{~K}$, which was the optimum condition obtained during 3DAP analysis for ULC steels. Typical elemental maps of Fe and C (G28) are shown in Figures $2 a$ and $2 b$, which were obtained through 3DAP reconstruction of the data obtained. Figure 2 clearly shows that the distribution of carbon is homogenous without any artifact. The concentrations of solute carbon in grain interior of each specimen are shown in Table 1 (right column). After skin pass, the carbon content in grain interior has increased $(\mathrm{Ab}<\mathrm{A})$, but it decreased with the increase of FDT $(\mathrm{G}<\mathrm{A})$.

When the starting carbon content was the same, the grain interior carbon concentration increased as grain size increased, showing the possibility of carbon content in grain interior manipulating grain size (Fig. 3). In the previous study, Soenen et al. (2004) reported that carbon segregated to grain boundaries during continuous annealing. However, carbon migration to grain boundary during aging is negligible, as the kinetics/binding energy of this process is much slower than that of the migration to dislocations. However, later, Vasilyev et al. (2008) investigated the aging process by means of the dynamic Young's modulus and dislocation amplitude-independent internal fraction changed measurements by acoustic methods, and found that a large additional amount of the interstitial atoms available for segregation on the dislocations appear in a solution after substantial incubation time under strain aging of steel. However, there is no observation of this change through microstructural analysis until now. In this study, the diffusion of grain boundary carbon to grain interior during aging is confirmed by 3DAP analysis of carbon for the first time.

Typical 3DAP elemental map of carbon cluster in G28 specimen is shown in Figure 2c. The number density increased with the increase of FDT temperature, and also after

Table 1. Average Grain Size and Average Carbon Content in Grain Interior Determined by Intrinsically Conductive Polymer (ICP) and Three-Dimensional Atom Probe (3DAP) of Each Specimen.

\begin{tabular}{|c|c|c|c|c|c|c|c|}
\hline \multirow[b]{2}{*}{ Code \# } & \multicolumn{3}{|c|}{$\begin{array}{l}\text { Average Grain Size } \\
\qquad(\mu \mathrm{m})\end{array}$} & \multicolumn{4}{|c|}{$\begin{array}{l}\text { Average Carbon Content in Grain Interior } \\
\qquad(\mathrm{ppm} / \mathrm{appm})\end{array}$} \\
\hline & $\mathrm{Ab}$ & A & G & ICP & Ab-3DAP & A-3DAP & G-3DAP \\
\hline 1 & $14.9 \pm 1.4$ & $18.2 \pm 1.9$ & $13.6 \pm 1.1$ & $14 / 65$ & $9 / 43$ & $16 / 74$ & $6 / 27$ \\
\hline 4 & $10.2 \pm 0.8$ & $10.3 \pm 0.6$ & $10.2 \pm 0.2$ & $44 / 204$ & $15 / 69$ & $18 / 85$ & $16 / 72$ \\
\hline 28 & $20.0 \pm 3.0$ & $24.5 \pm 4.2$ & $20.1 \pm 2.2$ & $12 / 56$ & $8 / 35$ & $16 / 76$ & $13 / 60$ \\
\hline
\end{tabular}




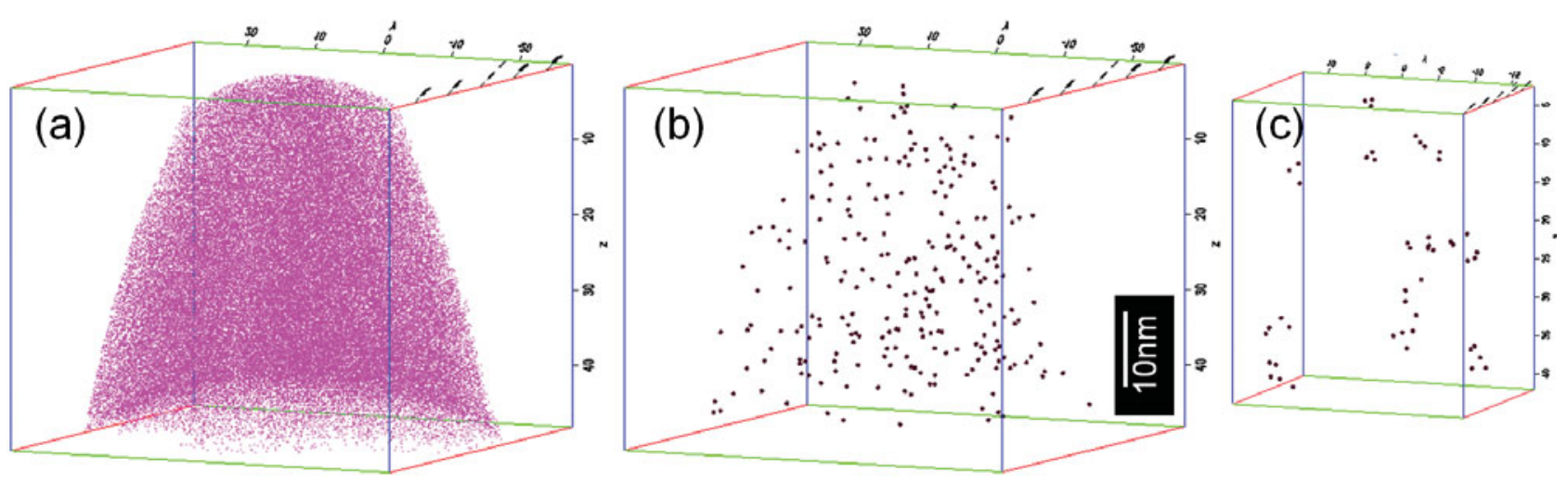

Figure 2. Typical three-dimensional atom probe (3DAP) reconstruction images of G28 specimen: (a) all ions, (b) carbon, and (c) carbon cluster.

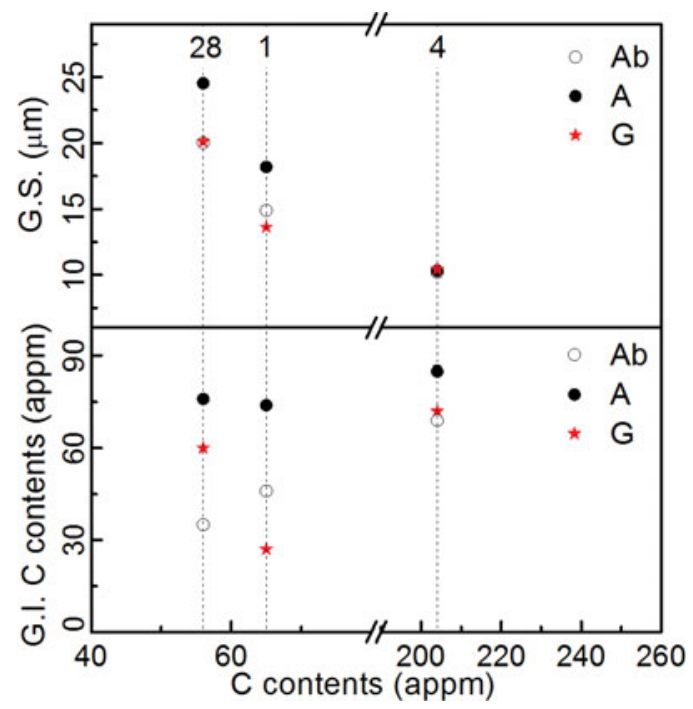

Figure 3. Relationship of grain size and carbon content in grain interior (determined by three-dimensional atom probe) in all the specimens.

aging at $200^{\circ} \mathrm{C}$ the number density of carbon cluster increased about $50 \%$, which indicates that cluster formation be accelerated by the annealing temperature.

\section{CONCLUSION}

1. The grain size and dislocation density decrease with the increase of carbon contents (12-44 ppm), and/or the increase of the FDT temperature.

2. The optimized condition of 3DAP for the accurate detection and quantitative analysis of the grain interior carbon in ULC steel is obtained and utilized.

3. For a given carbon content, the grain interior carbon concentration increases with grain size. The diffusion of grain boundary carbon to grain interior during aging is observed by 3DAP analysis of carbon.

4. 4. The carbon cluster in ULC steel $(\sim 1 \mathrm{~nm}$ in radius) is characterized, and its number density is increased with the FDT temperature. The number density of the clusters also increased about $50 \%$ upon aging at $200^{\circ} \mathrm{C}$, indicating that cluster formation is accelerated by the increase of the annealing temperature.

\section{ACKNOWLEDGMENTS}

This project was funded by the Sheet Products \& Process Research Group of POSCO, and supported by the Ministry of Knowledge Economy, Korea under the program of the Development of Strategic Technology (No. 10031739). This work was also supported by Changwon National University in 2011. We gratefully acknowledge the sponsor. The authors also thank Dr. Thomas F. Kelly, Dr. Dave Larson, and Dr. D. Lawrence from CAMECA Madison, and Dr. Gregory Thompson and Dr. Billie Wang from University of Alabama for 3DAP observations.

\section{ReFERENCES}

Berbenni, S., Favier, V., Lemoie, X. \& Berveiller, M. (2004). A micromechanical approach to model the bake hardening effect for low carbon steels. Script Mater 51, 303-308.

Cerezo, A. \& Davin, L. (2007). Aspects of the observation of clusters in the 3-dimensional atom probe. Surf Inter Anal 39, 184-188.

Heinrich, A., Kassab, T. \& Kirchheim, R. (2003). Investigation of the early stages of decomposition of $\mathrm{Cu}-0.7 \mathrm{at} . \%$ Fe with the tomographic atom probe. Mater Sci Eng A 353, 92-98.

Lee, J.M., Shibata, K., Asakura, K. \& Masumoto, Y. (2002). Observation of $\gamma \rightarrow \alpha$ transformation in ultralow-carbon steel under a high temperature optical microscope. ISIJ Inter 42, 1135-1143.

Miller, M.K. (2000). Atom Probe Tomography: Analysis at the Atomic Level. New York: Kluwer Academic/Plenum Press.

Soenen, B., De, A.K., Vandeputte, S. \& De Cooman, B.C. (2004). Competition between grain boundary segregation and Cottrell atmosphere formation during static strain aging in ultra low carbon bake hardening steels. Acta Mater 52, 3483-3492.

TAканалнi, M. (1974). Effect of manganese and sulfur on austenite grain size and recrystallized ferrite grain size after cold rolling of low carbon steel. ISIJ Inter 60, 501-513.

Vasilyev, A.A., Lee, H.C. \& Kuzmin, N.L. (2008). Nature of strain aging stages in bake hardening steel for automotive application. Mater Sci Eng A 485, 282-289.

ZhANG, Z., Lin, Q. \& Yu, Z. (2000). Grain boundary segregation in ultra-low carbon steel. Mater Sci Eng A 291, 22-26. 